\title{
Effect of Tungsten Addition on Phase Constitution and Magnetic Properties of the Bulk $\mathrm{Fe}_{65} \operatorname{Pr}_{9} \mathrm{~B}_{26-x} \mathrm{~W}_{x}$ Alloys
}

\author{
K. Filipecka*, P. Pawlik, K. Pawlik, P. Gębara, A. Przybye and M. Pruba \\ Institute of Physics, Faculty of Production Engineering and Materials Technology, \\ Częstochowa University of Technology, al. Armii Krajowej 19, 42-200 Częstochowa, Poland
}

(Received February 2, 2015)

\begin{abstract}
The effect of tungsten addition on phase constitution and magnetic properties of the bulk $\mathrm{Fe}_{65} \operatorname{Pr}_{9} \mathrm{~B}_{26}-x \mathrm{~W}_{x}$ (where $x=2,4,6,8$ ) alloys was studied. The base alloys were prepared by arc-melting of the high purity elements under Ar atmosphere. Samples were produced by suction of an arc-molten alloy to a water-cooled copper mould (the suction-casting method). In order to develop nanocrystalline structure, the samples were subjected to annealing. Heat treatment resulted in an evolution of the phase constitution that caused changes in magnetic properties of the alloys. X-ray diffractometry was used to determine the phase composition of annealed samples. The analysis showed presence of hard magnetic $\operatorname{Pr}_{2} \mathrm{Fe}_{14} \mathrm{~B}$, paramagnetic $\operatorname{Pr}_{1+x} \mathrm{Fe}_{4} \mathrm{~B}_{4}$ and soft ferromagnetic $\alpha$-Fe phases of annealed samples. The room temperature magnetic properties were determined from hysteresis loops measured by VSM magnetometer in the external magnetic field up to $2 \mathrm{~T}$. The highest hard magnetic parameters were measured for the rod sample of $\mathrm{Fe}_{65} \mathrm{Pr}_{9} \mathrm{~B}_{20} \mathrm{~W}_{6}$ annealed at $1003 \mathrm{~K}$ for $5 \mathrm{~min}$.
\end{abstract}

DOI: $10.12693 /$ APhysPolA.128.104

PACS: $75.50 . \mathrm{Ww}, 75.50 . \mathrm{Kj}, 71.20 . \mathrm{Eh}$

\section{Introduction}

The rapidly solidified bulk $\mathrm{RE}-\mathrm{Fe}-\mathrm{B}(\mathrm{RE}=$ rare earth $)$ magnets are of considerable interest due to their potential magnetic applications. Interesting properties in this group of alloys were observed in $\mathrm{Pr}-\mathrm{Fe}-\mathrm{B}$-type systems, in which $\operatorname{Pr}_{2} \mathrm{Fe}_{14} \mathrm{~B}$ phase is responsible for the high coercivity [1]. Values of saturation magnetization and the Curie temperature of the $\mathrm{Pr}_{2} \mathrm{Fe}_{14} \mathrm{~B}$ phase are comparable to this obtained for the $\mathrm{Nd}_{2} \mathrm{Fe}_{14} \mathrm{~B}$ [2]. However, it has a higher value of magnetocrystalline anisotropy field [3] and does not undergo a spin reorientation down to $4.2 \mathrm{~K}$ [4]. This factor causes that at low temperatures the $\operatorname{Pr}_{2} \mathrm{Fe}_{14} \mathrm{~B}$ phase exhibits superior magnetic properties. Therefore the $\mathrm{Pr}-\mathrm{Fe}-\mathrm{B}$ magnets are attractive for applications in wide range of temperatures. To improve the magnetic properties the composition of $\mathrm{Pr}-\mathrm{Fe}-\mathrm{B}$ alloys was modified many times. One of alloying elements, which is very interesting due to its influence on formation of hard magnetic $\mathrm{RE}_{2} \mathrm{Fe}_{14} \mathrm{~B}$ phase and improving the glass forming ability in iron alloy, is tungsten [511]. Furthermore, to obtain optimal magnetic properties, a selection of suitable conditions of technological process is crucial [12-16]. New methods for producing magnetic materials have been successfully implemented in recent years at the Institute of Physics of the Częstochowa University of Technology, namely the suctioncasting method [17]. In the present paper, ferromagnetic bulk alloys of the following compositions: $\mathrm{Fe}_{65} \mathrm{Pr}_{9} \mathrm{~B}_{24} \mathrm{~W}_{2}$, $\mathrm{Fe}_{65} \mathrm{Pr}_{9} \mathrm{~B}_{22} \mathrm{~W}_{4}, \mathrm{Fe}_{65} \mathrm{Pr}_{9} \mathrm{~B}_{20} \mathrm{~W}_{6}$ and $\mathrm{Fe}_{65} \mathrm{Pr}_{9} \mathrm{~B}_{18} \mathrm{~W}_{8}$ have been studied. The magnetic properties and analysis of

*corresponding author; e-mail: kasia.filipecka@onet.eu phase structure of the alloys in their as-cast state and after short-time annealing are presented.

\section{Experimental}

Samples of the $\mathrm{Fe}_{65} \mathrm{Pr}_{9} \mathrm{~B}_{26-x} \mathrm{~W}_{x}$ (where $x=2,4,6,8$ ) alloys were produced by arc-melting the high purity constituent $\mathrm{Fe}, \mathrm{Pr}, \mathrm{W}$ elements together with the pre-alloyed $\mathrm{Fe}-\mathrm{B}$ of known composition under an Ar atmosphere. The ingot samples were re-melted several times in order to get homogeneity. From the base alloys, the $1 \mathrm{~mm}$ diameter rods and $0.5 \mathrm{~mm}$ thick plates were produced by suction-casting of the melt into the water cooled copper die. The process was carried out under Ar atmosphere. Subsequently, the bulk samples were sealed in a quartz tube, under low pressure of $\mathrm{Ar}$ and annealed at $1003 \mathrm{~K}$ for $5 \mathrm{~min}$. The X-ray diffractometry (XRD) was used to determine the phase constitution of the samples. The XRD scans were measured using Bruker D8 Advance diffractometer with $\mathrm{Cu} K_{\alpha}$ radiation. The samples were crushed to powder in order to obtain XRD data representative for their entire volume. The magnetic properties at room temperature were measured using LakeShore 7307 vibrating sample magnetometer at external magnetic field up to $2 \mathrm{~T}$.

\section{Results and discussion}

The X-ray diffraction patterns recorded for the ascast $1 \mathrm{~mm}$ rod and $0.5 \mathrm{~mm}$ thick plate samples of $\mathrm{Fe}_{65} \mathrm{Pr}_{9} \mathrm{~B}_{26-x} \mathrm{~W}_{x}$ (where $x=2,4,6,8$ ) alloys are shown in Fig. 1. It was shown that for the as-cast bulk samples crystallization of hard magnetic $\mathrm{Pr}_{2} \mathrm{Fe}_{14} \mathrm{~B}$ and paramagnetic $\mathrm{Pr}_{1+x} \mathrm{Fe}_{4} \mathrm{~B}_{4}$ phases took place. Furthermore, the increase of $\mathrm{W}$ contents resulted in significant decrease of peaks intensities corresponding to the $\alpha$-Fe phase. Due to the low volume fraction of the crystalline phase, only XRD peaks of high intensities are observed, while the lower intensity peaks are diffused within the background. 

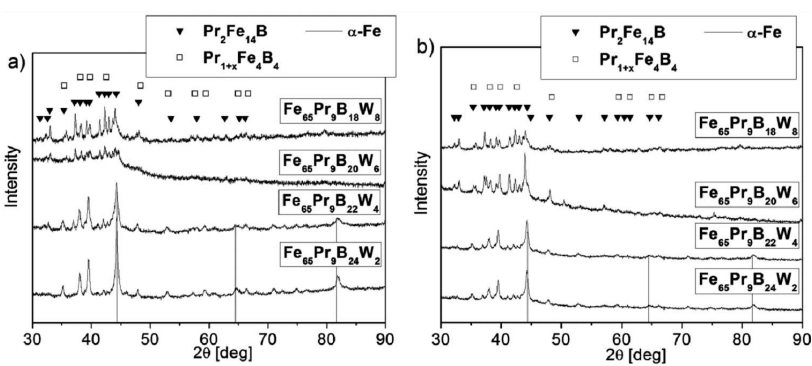

Fig. 1. XRD diffraction patterns of as-cast $1 \mathrm{~mm}$ rods (a) and $0.5 \mathrm{~mm}$ thick plates (b) of $\mathrm{Fe}_{65} \operatorname{Pr}_{9} \mathrm{~B}_{26-x} \mathrm{~W}_{x}$ (where $x=2,4,6,8$ ) alloy.

In Fig. 2 the XRD scans recorded for the $1 \mathrm{~mm}$ rod and $0.5 \mathrm{~mm}$ thick plate samples of $\mathrm{Fe}_{65} \operatorname{Pr}_{9} \mathrm{~B}_{26-x} \mathrm{~W}_{x}$ (where $x=2,4,6,8)$ alloys, subjected to annealing at $1003 \mathrm{~K}$ for $5 \mathrm{~min}$, were shown. The phase analysis confirmed the presence of hard magnetic $\operatorname{Pr}_{2} \mathrm{Fe}_{14} \mathrm{~B}$, paramagnetic $\mathrm{Pr}_{1+x} \mathrm{Fe}_{4} \mathrm{~B}_{4}$ and $\alpha$-Fe soft phases. For the annealed samples, the peaks were more pronounced, that suggested growth of the crystalline phases during annealing. For samples containing 6 and 8 at.\% of $\mathrm{W}$, no evidence of presence of $\alpha$-Fe phase was shown.
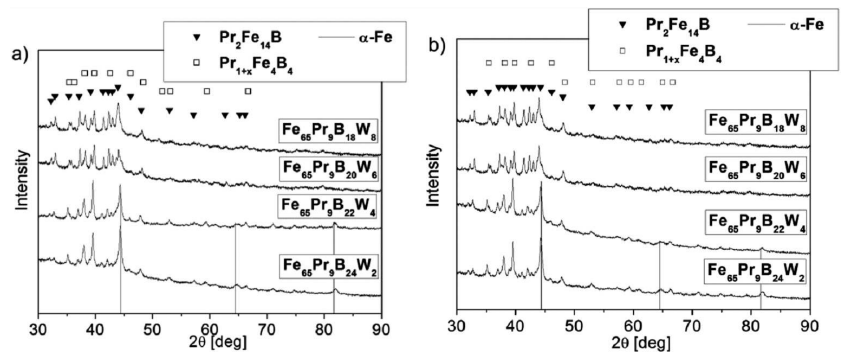

Fig. 2. XRD diffraction patterns of $1 \mathrm{~mm}$ rods (a) and $0.5 \mathrm{~mm}$ thick plates (b) of $\mathrm{Fe}_{65} \operatorname{Pr}_{9} \mathrm{~B}_{26-x} \mathrm{~W}_{x}$ (where $x=$ $2,4,6,8$ ) alloys annealed at $1003 \mathrm{~K}$ for $5 \mathrm{~min}$.

The magnetic hysteresis loops measured for the ascast and annealed at $1003 \mathrm{~K}$ for 5 min rods of all alloys compositions are shown in Fig. 3. The as-cast rods of $\mathrm{Fe}_{65} \mathrm{Pr}_{9} \mathrm{~B}_{24} \mathrm{~W}_{2}$ and $\mathrm{Fe}_{65} \mathrm{Pr}_{9} \mathrm{~B}_{22} \mathrm{~W}_{4}$ alloys had low coercivity ${ }_{\mathrm{J}} H_{\mathrm{c}}$. Short time annealing of those samples in $1003 \mathrm{~K}$ for 5 min does not improve their magnetic properties. This behavior suggests that annealing of those samples did not affect in significant extent the phase constitution and their microstructure. The wasp-waisted shape of hysteresis loop measured for the as-cast $\mathrm{Fe}_{65} \mathrm{Pr}_{9} \mathrm{~B}_{20} \mathrm{~W}_{6}$ rods suggests a presence of low fraction of hard magnetic phase embedded in the amorphous matrix. However, annealing of samples containing 6 and 8 at. $\%$ of $\mathrm{W}$ at $1003 \mathrm{~K}$ for $5 \mathrm{~min}$ resulted in rise of the coercivity ${ }_{\mathrm{J}} H_{\mathrm{c}}$ and significant change of the shape of hysteresis loop and thus increase of the maximum magnetic energy product $(B H)_{\max }$. This is due to the nucleation and growth of hard magnetic $\operatorname{Pr}_{2} \mathrm{Fe}_{14} \mathrm{~B}$ phase during annealing. Especially, the $\mathrm{Fe}_{65} \mathrm{Pr}_{9} \mathrm{~B}_{20} \mathrm{~W}_{6}$ alloy rods subjected
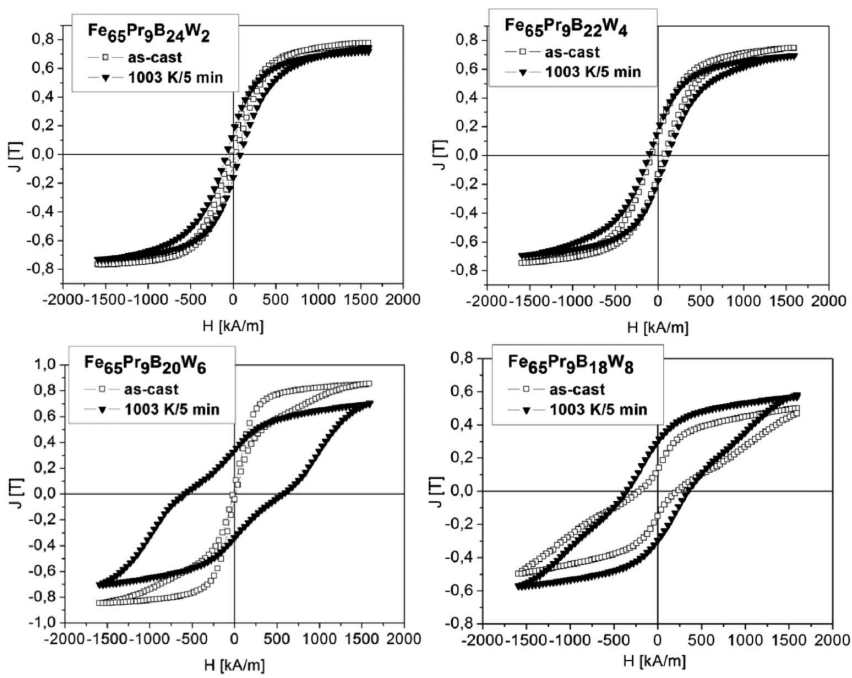

Fig. 3. The hysteresis loops measured of rod samples $\mathrm{Fe}_{65} \mathrm{Pr}_{9} \mathrm{~B}_{26-x} \mathrm{~W}_{x}$ (where $x=2,4,6,8$ ) in as-cast state and annealed at $1003 \mathrm{~K}$ for $5 \mathrm{~min}$.
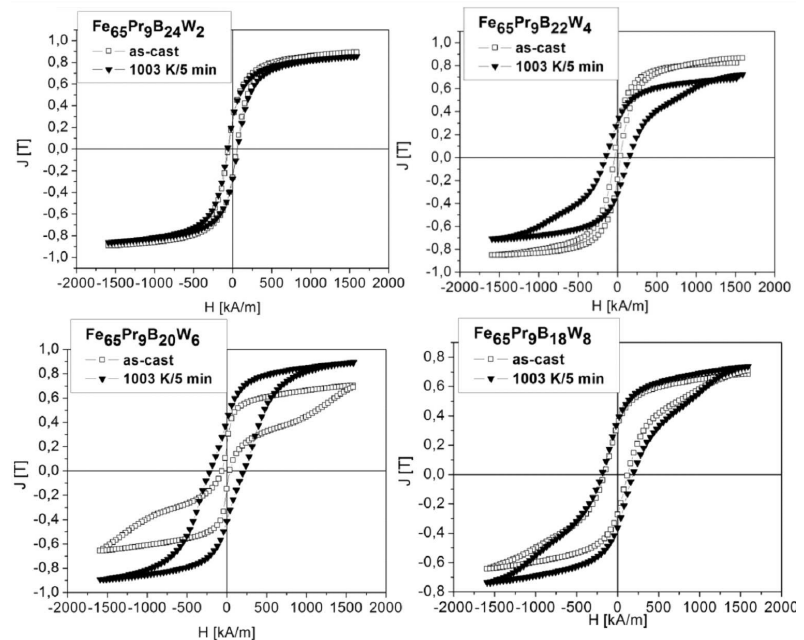

Fig. 4. The hysteresis loops measured of plate samples $\mathrm{Fe}_{65} \mathrm{Pr}_{9} \mathrm{~B}_{26-x} \mathrm{~W}_{x}$ (where $x=2,4,6,8$ ) in as-cast state and annealed at $1003 \mathrm{~K}$ for $5 \mathrm{~min}$.

to annealing at $1003 \mathrm{~K}$ for 5 min has the highest coercive field ${ }_{\mathrm{J}} H_{\mathrm{c}}=580 \mathrm{kA} / \mathrm{m}$ and $(B H)_{\max } \approx 14 \mathrm{~kJ} / \mathrm{m}^{3}$ in a group of rod samples were measured.

Similar shapes of the hysteresis loops were observed for plates of $\mathrm{Fe}_{65} \mathrm{Pr}_{9} \mathrm{~B}_{26-x} \mathrm{~W}_{x}$ alloys (Fig. 4). For the lowest $\mathrm{W}$ contents $(2$ at.\% of $\mathrm{W})$ the annealing had no effect in the change of their magnetic properties. This suggests no change of their phase constitution during annealing. Lower coercivity of the as-cast $\mathrm{Fe}_{65} \mathrm{Pr}_{9} \mathrm{~B}_{24} \mathrm{~W}_{4}$ alloy, in comparison to ${ }_{\mathrm{J}} H_{\mathrm{c}}$ measured for rods of the same composition, is due to higher cooling rate of the plates. Therefore annealing leads to increase of their coercivity caused by significant change of their phase constitution. In the case of higher $\mathrm{W}$ additions, an increase in the coercive field ${ }_{\mathrm{J}} H_{\mathrm{c}}$ and magnetic energy product $(B H)_{\max }$ is observed. The maximum values of these parameters 
reach plate sample of the $\mathrm{Fe}_{65} \mathrm{Pr}_{9} \mathrm{~B}_{20} \mathrm{~W}_{6}$ alloy annealed at $1003 \mathrm{~K}$ for $5 \mathrm{~min}$.

The magnetic properties of $\mathrm{Fe}-\mathrm{Pr}-\mathrm{B}-\mathrm{W}$ type alloys obtained by suction-casting method, are collected in Table.

TABLE

Magnetic properties of the bulk samples of $\mathrm{Fe}_{65} \operatorname{Pr}_{9} \mathrm{~B}_{26-x} \mathrm{~W}_{x}$ (where: $x=2,4,6,8$ ) alloys in as-cast state and after annealing.

\begin{tabular}{|c|c|c|c|c|}
\hline \multirow{2}{*}{\multicolumn{2}{|c|}{$\begin{array}{c}\text { Material and heat } \\
\text { treatment }\end{array}$}} & \multicolumn{3}{|c|}{ Magnetic properties } \\
\hline & & $\begin{array}{c}\mathrm{J} H_{\mathrm{c}} \\
{[\mathrm{kA} / \mathrm{m}]}\end{array}$ & $\begin{array}{c}J_{\mathrm{r}} \\
{[\mathrm{T}]}\end{array}$ & $\begin{array}{c}(B H)_{\max } \\
{\left[\mathrm{kJ} / \mathrm{m}^{3}\right]}\end{array}$ \\
\hline & & \multicolumn{3}{|c|}{$\mathrm{Fe}_{65} \operatorname{Pr}_{9} \mathrm{~B}_{24} \mathrm{~W}_{2}$} \\
\hline \multirow[t]{2}{*}{ rod } & as-cast & 34 & 0.1 & 0.04 \\
\hline & $1003 \mathrm{~K} / 5 \mathrm{~min}$ & 81 & 0.15 & 0.3 \\
\hline \multirow[t]{3}{*}{ plate } & as-cast & 53 & 0.23 & 2.9 \\
\hline & $1003 \mathrm{~K} / 5 \mathrm{~min}$ & 66 & 0.23 & 3.4 \\
\hline & & \multicolumn{3}{|c|}{$\mathrm{Fe}_{65} \operatorname{Pr}_{9} \mathrm{~B}_{22} \mathrm{~W}_{4}$} \\
\hline \multirow[t]{2}{*}{ rod } & as-cast & 74 & 1.13 & 1.4 \\
\hline & $1003 \mathrm{~K} / 5 \mathrm{~min}$ & 108 & 1.18 & 2.4 \\
\hline \multirow[t]{3}{*}{ plate } & as-cast & 39 & 0.16 & 1.2 \\
\hline & $1003 \mathrm{~K} / 5 \mathrm{~min}$ & 151 & 0.30 & 7.0 \\
\hline & & \multicolumn{3}{|c|}{$\mathrm{Fe}_{65} \operatorname{Pr}_{9} \mathrm{~B}_{20} \mathrm{~W}_{6}$} \\
\hline \multirow[t]{2}{*}{ rod } & as-cast & - & - & - \\
\hline & $1003 \mathrm{~K} / 5 \mathrm{~min}$ & 580 & 0.34 & 14.1 \\
\hline \multirow[t]{3}{*}{ plate } & as-cast & 60 & 0.18 & 1.6 \\
\hline & $1003 \mathrm{~K} / 5 \mathrm{~min}$ & 210 & 0.41 & 12.2 \\
\hline & & \multicolumn{3}{|c|}{$\mathrm{Fe}_{65} \mathrm{Pr}_{9} \mathrm{~B}_{18} \mathrm{~W}_{8}$} \\
\hline \multirow[t]{2}{*}{$\operatorname{rod}$} & as-cast & 219 & 0.14 & 2.5 \\
\hline & $1003 \mathrm{~K} / 5 \mathrm{~min}$ & 354 & 0.29 & 10.9 \\
\hline \multirow[t]{2}{*}{ plate } & as-cast & 145 & 0.29 & 8.4 \\
\hline & $1003 \mathrm{~K} / 5 \mathrm{~min}$ & 193 & 0.35 & 10.9 \\
\hline
\end{tabular}

\section{Conclusion}

The paper presents the results of the structural and magnetic studies of bulk $\mathrm{Fe}_{65} \operatorname{Pr}_{9} \mathrm{~B}_{26-x} \mathrm{~W}_{x}$ (where $x=2$, $4,6,8$ ) alloys produced by suction-casting technique. $\mathrm{X}$ ray diffraction patterns showed a presence of hard magnetic $\operatorname{Pr}_{2} \mathrm{Fe}_{14} \mathrm{~B}$ and paramagnetic $\operatorname{Pr}_{1+x} \mathrm{Fe}_{4} \mathrm{~B}_{4}$ phases in samples in the as-cast state and subjected to annealing. Furthermore, for the $x=2$ and 4 alloys the presence of soft magnetic $\alpha$-Fe phase was revealed. However, for samples containing 6 and 8 at.\% of W, no evidence of a presence of $\alpha$-Fe phase was shown. The bulk $\mathrm{Fe}_{65} \mathrm{Pr}_{9} \mathrm{~B}_{24} \mathrm{~W}_{2}$ and $\mathrm{Fe}_{65} \mathrm{Pr}_{9} \mathrm{~B}_{22} \mathrm{~W}_{4}$ alloys in as-cast state and subjected to annealing had a low coercivity ${ }_{\mathrm{J}} H_{\mathrm{c}}$ and magnetic energy product $(B H)_{\max }$. Addition of tungsten to the base composition of the alloys resulted in increase of the magnetic parameters. The maximum ${ }_{\mathrm{J}} H_{\mathrm{c}}$ and $(B H)_{\max }$ were measured for the rod sample of $\mathrm{Fe}_{65} \operatorname{Pr}_{9} \mathrm{~B}_{20} \mathrm{~W}_{6}$ annealed at $1003 \mathrm{~K}$ for $5 \mathrm{~min}$.

\section{References}

[1] J.F. Herbst, W.B. Yelon, J. Appl. Phys. 57, 2343 (1985).

[2] E.P. Wohlfarth, K.H.J. Buschow, Ferromagnetic Materials, North-Holland, Amsterdam 1988, p. 20 Table 4.

[3] S. Hirosawa, Y. Matsuura, H. Yamamoto, S. Fujimura, M. Sagawa, H. Yamauchi, J. Appl. Phys. 59, 873 (1986).

[4] E.B. Boltich, W.E. Wallace, Solid State Commun 55, 529 (1985).

[5] W. Rodewald, P. Scherey, J. Magn. Magn. Mater 83, 206 (1990).

[6] J. Bernardi, J. Fidler, F. Födermayr, IEEE Trans. Magn. 28, 2127 (1992).

[7] A. Yan, X. Song, X. Wang, IEEE Trans. Magn. 36 2033 (2000).

[8] A. Yan, W. Song, M. Song, W. Wang, J. Alloys Comp. 257, 273 (1997).

[9] J.F. Herbst, J.J. Croat, J. Magn. Magn. Mater 100, 57 (1991).

[10] B. Xiaoqian, Z. Jie, L. Wei, G. Xuexu, Z. Shouzeng, J. Rare Earth 27, 843 (2000).

[11] A. Przybył, J.J. Wysłocki, J. Mater. Process. Technol. 175, 352 (2006).

[12] A. Przybył, K. Pawlik, P. Pawlik, P. Gębara, J.J. Wysłocki, J. Alloys Comp. 536, 333 (2012).

[13] K. Pawlik, P. Pawlik, J.J. Wysłocki, W. Kaszuwara, J. Alloys Comp. 536, 348 (2012).

[14] K. Pawlik, J. Bednarcik, P. Pawlik, J.J. Wysłocki, W. Kaszuwara, B. Michalski, P. Gębara, Phys. Status Solidi C 7, 1336 (2010).

[15] P. Pawlik, K. Pawlik, H.A. Davies, J.J. Wysłocki, P. Gębara, Phys. Status Solidi A 207, 1174 (2010).

[16] K. Filipecka, K. Pawlik, P. Pawlik, J.J. Wysłocki, P. Gebara, A. Przybył, Acta Phys. Pol. A 126, 164 (2014).

[17] J.J. Wysłocki, P. Pawlik, J. Achievem. Mater. Manufact. Eng. 43, 463 (2010). 